\title{
Transport of Metallic Ions through Polyaniline-Containing Composite Membranes
}

\author{
Carlos A. Ferreira, ${ }^{*}, \dagger$ Jordi Casanovas, ${ }^{*}$ Marco A. S. Rodrigues, ${ }^{\S}$ Francielli Müller, ${ }^{\dagger}$ Elaine Armelin,,$\perp \perp$ and \\ Carlos Alemán $*, l, \perp$
}

Universidade Federal do Rio Grande do Sul, PPGEM, Av. Bento Gonçalves, 9500, Setor 4, Prédio 74, Cep. 91501-970, Porto

Alegre, RS, Brazil, Departament de Química, Escola Politècnica Superior, Universitat de Lleida, c/Jaume II no. 69,

Lleida E-25001, Spain, Centro Universitário Feevale, ICET, RS 239-2755, Cep. 93352-000, Novo Hamburgo, RS, Brazil,

Departament d'Enginyeria Química, ETS d'Enginyers Industrials de Barcelona, Universitat Politècnica de Catalunya, Avda.

Diagonal 647, Barcelona E-08028, Spain, and Center for Research in Nano-Engineering, Universitat Politècnica de Catalunya,

Campus Sud, Edifici C', C/Pasqual i Vila s/n, Barcelona E-08028, Spain

\begin{abstract}
The extraction of $\mathrm{Na}^{+}, \mathrm{Ni}^{2+}$, and $\mathrm{Cr}^{3+}$ using six different membranes made of polyaniline composited with high-impact polystyrene, which differ in the doping agent and/or the preparation method, has been investigated. The swelling and ion-exchange capacities of the six polyaniline composited with high-impact polysterene (HIPS/PAni) membranes have been determined and compared with that of the commercial Selemion membrane. Electrodialysis tests using a five-compartment cell evidenced that the extraction of ions depends on the electronic structure of the $\mathrm{SO}_{3}{ }^{-}$groups, which is modulated by the doping agent, and on both microstructure and electrical resistance of the membrane, which are regulated by the preparation method. The transport of ions through HIPS/PAni and Selemion membranes was found to be comparable. Quantum mechanical calculations on model complexes have been performed to characterize the electronic structure of the dopants. Results indicate that the strength of the interaction between the different doping agents and the polyaniline is inversely proportional to the concentration of negative charge in the $\mathrm{SO}_{3}{ }^{-}$group of the former. Moreover, both the binding energy and the distribution of charges calculated for dopant $\cdots$ PAni complexes have been compared with those predicted for dopant $\cdots$ metallic ion complexes.
\end{abstract}

\section{Introduction}

Conducting polymers (CPs), that is, electroactive conjugated polymers, are organic materials with an enormous projection because their properties are useful for a wide number of potential technological applications. ${ }^{1-4}$ Among these materials, polyaniline (PAni) is particularly interesting because of its high chemical and environmental stabilities, remarkable electrical conductivity in the doped state, easy processability, and low cost. Thus, in the last few years PAni has been successfully used for a wide variety of applications: anticorrosive additive for organic coatings, ${ }^{5,6}$ solid state ion-selective electrodes, ${ }^{7}$ electrochromic devices for optical displays, ${ }^{8,9}$ chemical sensors and biosensors, ${ }^{10,11}$ electrochemical capacitors, ${ }^{12,13}$ and ionselective membranes for electrodialysis. ${ }^{14-17}$

Electrodialysis with ion-selective membranes is an advanced separation technology that is currently used in different fields: concentration of seawater to produce edible salt, desalination of saline water, separation of ionic materials from nonionic materials, recovery of metal ions contained in the effluents produced by the galvanic industry, and so forth. This technology is based on the use of an electric field as a driving force to transport ions from one solution to another through an electrodialysis stack, which is constituted by cation- and anion-

\footnotetext{
* Corresponding authors. E-mail: ferreira.carlos@ufrgs.br and carlos.aleman@upc.edu.

Universidade Federal do Rio Grande do Sul.

$\doteqdot$ Universitat de Lleida.

§ Centro Universitário Feevale.

"Departament d'Enginyeria Química, Universitat Politècnica de Catalunya.

${ }^{\perp}$ Center for Research in Nano-Engineering, Universitat Politècnica de Catalunya.
}

selective membranes alternatively arranged. Within this field, some of us have prepared and examined the performance of cationic membranes made of PAni composited with high-impact polysterene (HIPS/PAni) for the treatment of zinc solutions, which is frequently present in industrial effluents. ${ }^{15-17}$ HIPS was used to impart mechanical resistance to the membrane since the mechanical properties of PAni are very poor.

Membranes were prepared with a screw extruder mixing mechanically a HIPS and PAni emeraldine base (EB), which was doped with dodecylbenzenesulfonic acid (DBSA), $p$ toluenesulfonic acid (TSA), and canphorsulfonic acid (CSA). ${ }^{15,16}$ The swelling and ion-exchange capacities, chemical stability, electrical conductivity, thermal behavior, and electrodialysis were determined for the produced membranes. Results indicated that membranes in which PAni was doped with CSA and TSA present good $\mathrm{Zn}^{2+}$ transport as well as percent extraction compared to the commercial membrane Nafion 450, while the membrane with DBSA has a low transport number of $\mathrm{Zn}^{2+}$ ions. More recently, the same membranes were prepared by dispersing tetrachloroethylene solutions of HIPS and doped PAni. ${ }^{17}$ In all cases ion transport was found to be better for membranes prepared by solvent dissolution than for those produced by mechanical mixture in screw extruder, even though the best results were obtained when CSA was used as a doping agent.

The aim of this work is to examine and rationalize the influence of the oxidation state in the ion transport through the HIPS/PAni composite membranes. Specifically, we investigated the extraction of $\mathrm{Na}^{+}, \mathrm{Ni}^{2+}$, and $\mathrm{Cr}^{3+}$ using six different membranes, which were obtained considering two preparation methods (mechanical mixture and solvent dissolution) and three doping agents for PAni (DBSA, CSA, and TSA). Moreover, 
Table 1. Characteristics of the HIPS/PAni Membranes Studied in This Work

\begin{tabular}{cll}
\hline membrane & preparation method & dopant \\
\hline MCP & mechanical mixture & CSA \\
MCS & solvent dissolution & CSA \\
MDP & mechanical mixture & DBSA \\
MDS & solvent dissolution & DBSA \\
MTP & mechanical mixture & TSA \\
MTS & solvent dissolution & TSA
\end{tabular}

the results of the produced membranes have been compared with those of commercial Selemion membrane. In addition to the experimental developments required for this investigation, which involve the preparation and characterization of the membranes, and the electrodialysis assays, a complementary theoretical study using density functional theory (DFT) and ab initio quantum mechanical calculations has been carried out to provide helpful information at the microscopic level and to rationalize the observations. More specifically, the strength of the interaction between the dopant and the CP and the charge transfer from the former to the latter have been examined by analyzing the following complexes: CSA $\cdots$ PAni, TSA $\cdots$ PAni, and PBSA $\cdots$ PAni, where the $\mathrm{CP}$ have been represented using model molecules containing two, four, and six repeating units. In addition, CSA $\cdots M$, TSA $\cdots M$, and PBSA $\cdots$ M complexes with $\mathrm{M}=\mathrm{Na}^{+}, \mathrm{Ni}^{2+}$, and $\mathrm{Cr}^{3+}$ have been investigated to get microscopic information of the interaction between the dopant and the different metallic ions.

\section{Methods}

Membrane Preparation. Aniline (nuclear), $\left(\mathrm{NH}_{4}\right)_{2} \mathrm{~S}_{2} \mathrm{O}_{8}$ (Synth), $\mathrm{HCl}$ (nuclear), and $\mathrm{NH}_{4} \mathrm{OH}$ (Synth) were used in the PAni EB synthesis, which was performed using a standard method reported elsewhere. ${ }^{18,19}$ The resulting polymer was doped with DBSA (Lavrex), CSA (Aldrich), or TSA (Vetec) considering a concentration of $1.5 \mathrm{M}$ in all cases and stirring the solution for $24 \mathrm{~h}$.

Membranes were prepared using two different procedures to mix HIPS (Innova S.A.) and PAni, which allowed us to evaluate the effect of the production method. In the first method, hereafter denoted the mechanical mixture, HIPS (8 g) and PAni $(2 \mathrm{~g})$ were mixed in a MH-100 mixer and then pelletized. For film preparation, pellets were pressed in a Carver model $\mathrm{C}$ heating press at $180{ }^{\circ} \mathrm{C}$ to avoid decomposition. In the second method, denoted solvent dissolution, HIPS ( $8 \mathrm{~g}$ ) and PAni (2 g) were dissolved in $25 \mathrm{~mL}$ of tetrachloroethylene (synth), a common solvent for both materials. After dissolution, PAni was dispersed in the HIPS matrix for $30 \mathrm{~min}$ using a Fisaton mixer at 1500 rpm. The membranes were modeled on glass plates using a laminator to keep thickness constant, and the solvent was evaporated slowly for $24 \mathrm{~h}$ under room temperature. Table 1 lists the abbreviations used to denote produced membranes, specifying the preparation method and the organic dopant in each case.

Membrane Characterization. Membranes were equilibrated in deionized water at room temperature for $24 \mathrm{~h}$. The excess of water was removed with filter paper, and the membranes were weighed and kept in an oven at $80^{\circ} \mathrm{C}$ for $12 \mathrm{~h}$ and then weighted again. The uptake of water was determined by the mass difference between the wet and the dried membranes (after heating at $80{ }^{\circ} \mathrm{C}$ ). Water absorption has been expressed in percentage. $^{20-22}$

To determine the ion-exchange capacity (IEC), the membranes were equilibrated in $100 \mathrm{~mL}$ of $1 \mathrm{M} \mathrm{HCl}$ solution for $72 \mathrm{~h}$. After that, they were removed from the solution, and the

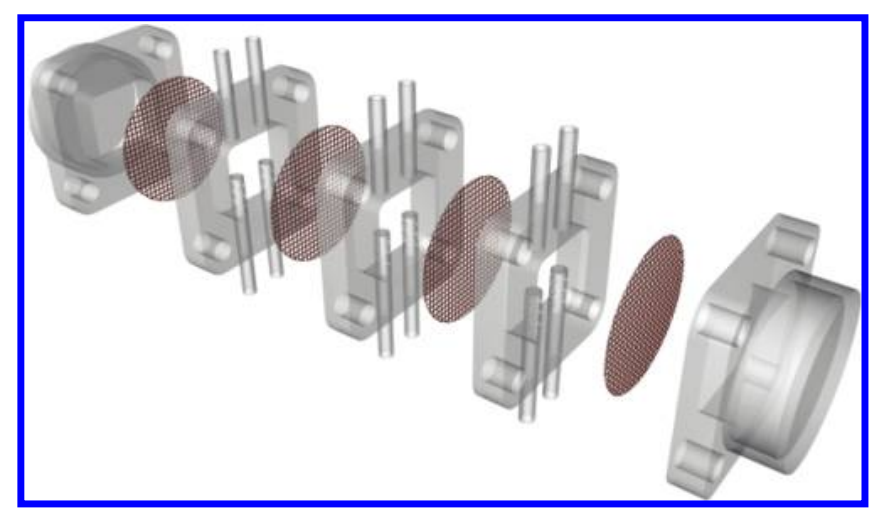

Figure 1. Five-compartment cell used for electrodialysis.

excess of acid was eliminated by washing with distilled water. Next, membranes were immersed in $1 \mathrm{M} \mathrm{NaCl}$ to exchange $\mathrm{H}^{+}$ by $\mathrm{Na}^{+}$, three renewed solutions being used in this process. The amount of $\mathrm{H}^{+}$in such three solutions was determined by titration with $0.005 \mathrm{M} \mathrm{NaOH}$. The IEC was expressed in milliequivalents of $\mathrm{H}^{+}$per gram of dry membrane. ${ }^{22}$

Electrodialysis. $\mathrm{NaCl}, \mathrm{NiCl}_{2}$, and $\mathrm{CrCl}_{3}$ (Vetec) were used in the electrodialysis tests. Assays were conducted using a fivecompartment cell, as shown in Figure 1. Platinized titanium electrodes were used as the anode and cathode. The volume in all compartments was $500 \mathrm{~mL}$. Membranes were immersed in the working solutions for $48 \mathrm{~h}$ to reach the equilibrium. A pseudostationary state was achieved with a 15 min preelectrodialysis assay. After this, solutions were replaced by new ones, and the experiment was restarted. Solutions were prepared with distilled and deionized water. The anionic membrane was a Selemion AMT (Asahi Glass Co.), while the cathodic membranes were those prepared in this work and the commercial Selemion (Asahi Glass Co.), which was used for comparison.

Tests were conducted by applying a current density of ( 3 and 5) $\mathrm{mA} \cdot \mathrm{cm}^{-2}$ for the membranes prepared by solvent dissolution and by pressing the mechanical mixture, respectively. Assays took $240 \mathrm{~min}$ for each one, and all of them were conducted at room temperature. The effective area of the membranes was $10 \mathrm{~cm}^{2}$. The solution used to evaluate the transport of $\mathrm{Na}^{+}, \mathrm{Ni}^{2+}$, and $\mathrm{Cr}^{3+}$ were $0.1 \mathrm{M} \mathrm{NaCl}, 0.1 \mathrm{M} \mathrm{NiCl}_{2}$, and $0.1 \mathrm{M} \mathrm{CrCl}_{3}$, respectively.

Polarization Curves. The limiting current density $\left(i_{\mathrm{lim}}\right)$ was derived from the variation of the membrane potential $\left(\phi_{\mathrm{m}}\right)$ against the applied current density $(i){ }^{23}$ The $i-\phi_{\mathrm{m}}$ curves were obtained in a five-compartment electrodialysis cell (Figure 1), constituted by an ion-selective membrane separating two compartments filled by the same electrolyte solution. The value of $i$ was increased every two minutes, and the corresponding $\phi_{\mathrm{m}}$ was determined using two reference electrodes put close to the surface of the membrane.

Chemical Analyses. Flame photometric determinations with a Digimed DM-61 flame photometer were used to obtain the concentration of $\mathrm{Na}^{+}$. On the other hand, the concentration of $\mathrm{Ni}^{2+}$ and $\mathrm{Cr}^{3+}$ was obtained by potentiometric titration and atomic absorption (Jasco model 7800), respectively.

Quantum Mechanical Calculations. To model the interactions between PAni-ES and the doping agents, the $\mathrm{CP}$ was described using model molecules in the radical cation state that involved two, four, or six phenyl-nitrogen $(\mathrm{Ph}-\mathrm{N})$ repeating units blocked at one end by a hydrogen atom and at the other end by a nitrogen atom in the amine form. These models of PAni correspond to $x=0,1$, and 2 in Scheme 1 and have been denoted 2-PAni, 4-PAni, and 6-PAni, respectively, that is, $(2 x$ 
Scheme 1

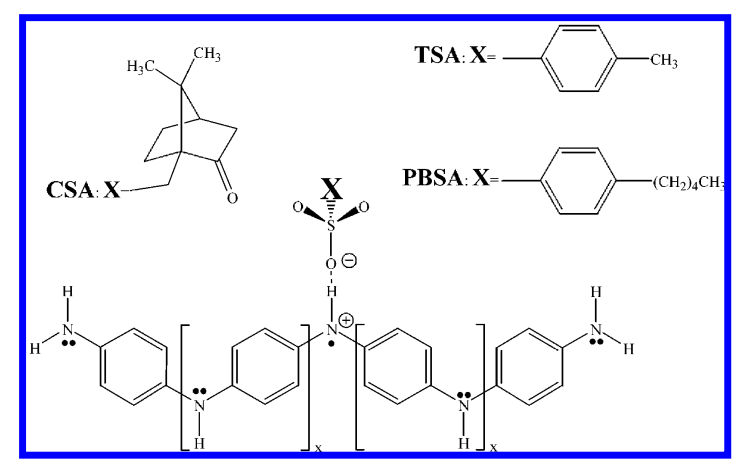

+ 2)-PAni. The deprotonated forms of the CSA and TSA were represented explicitly, while pentylbenzenesulfonate (PBSA) was used to model deprotonated DBSA. The reduction of the dodecyl group to the pentyl one is based on a recent study devoted to model the interaction between alkylsulfonate anions and PAni-ES, in which we showed that the strength and the electronic characteristics of such interaction is not affected by the length of the alkyl group. ${ }^{24}$ The chemical structures of the deprotonated forms of CSA, TSA, and PBSA are included in Scheme 1.

Initially, complete geometry optimizations of the oligoanilines and the doping agents were performed separately. After this, the interaction between each dopant and $(2 x+2)$-PAni was examined by performing complete geometry optimizations of complexes with the anion arranged with respect to the reactive center of the oligoaniline as in Scheme 1. DFT calculations were performed using the Becke's three-parameter hybrid functional (B3) ${ }^{25}$ combined with the expression developed by Lee, Yang, and Parr (LYP) for the nonlocal correlation. ${ }^{26}$ The unrestricted formalism of this exchange-correlation functional (UB3LYP) was combined with the $6-31 \mathrm{G}(\mathrm{d})$ basis set. ${ }^{27}$ The $\mathrm{S}-\mathrm{O} \cdots \mathrm{H}-\mathrm{N}$ interaction between the dopant and $(2 x+2)$-PAni was characterized using the following geometric parameters: the $\mathrm{O} \cdots \mathrm{H}$ distance $\left(d_{\mathrm{O}} \cdots_{\mathrm{H}}\right)$ and the $<\mathrm{O} \cdots \mathrm{H}-\mathrm{N}$ angle.

On the other hand, complete geometry optimizations of CSA $\cdots \mathrm{M}$, TSA $\cdots \mathrm{M}$, and PBSA $\cdots \mathrm{M}$ complexes with $\mathrm{M}=$ $\mathrm{Na}^{+}, \mathrm{Ni}^{2+}$, and $\mathrm{Cr}^{3+}$ were performed using both the UB3LYP 25,26 and UMP2 ${ }^{28}$ quantum mechanical methods combined with the $6-31 \mathrm{G}(\mathrm{d})^{27}$ and $6-31+\mathrm{G}(\mathrm{d}, \mathrm{p})^{29}$ basis sets, respectively. Thus, as the $\mathrm{SO}_{3}{ }^{-}$groups are responsible for the ionic transport in HIPS/PAni membranes, a comparison between the electronic characteristics of this moiety in dopant $\cdots(2 x+2)$-PAni and dopant $\cdots$ M complexes is highly desirable.

For each dopant $\cdots(2 x+2)$-PAni and dopant $\cdots$ M complex, the interaction energy, $\Delta E_{\text {int }}$, was evaluated as the difference between the energy of the complex and the sum of the energies calculated for the isolated fragments. The basis set superposition error (BSSE) derived from the use of a limited basis set was taken into account by correcting the $\Delta E_{\text {int }}$ values with the counterpoise method. ${ }^{30}$ The distribution of charges in the complexes was evaluated by applying full natural bond orbital (NBO) analyses ${ }^{31,32}$ to the calculated UB3LYP/6-31G(d) and UMP2/6-31+G(d,p) wave functions. The occupation numbers of the natural atomic orbitals led to the NBO charges. All calculations were carried out using the Gaussian 03 computer program. $^{33}$

\section{Results and Discussion}

Swelling and Ion-Exchange Capacities. The dimensional stability and the resistance to ion transport through the mem-
Table 2. Thickness, Swelling Capacity, and Ion-Exchange Capacity (IEC) of the Membranes Studied in This Work

\begin{tabular}{lccc}
\hline membrane & thickness $(\mathrm{mm})$ & swelling $(\%)$ & IEC $^{a}$ \\
\hline MCP & 0.15 to 0.20 & 4 & 0.12 \\
MCS & 0.10 to 0.15 & 9 & 0.20 \\
MDP & 0.15 to 0.20 & 4 & 0.12 \\
MDS & 0.10 to 0.15 & 7 & 0.15 \\
MTP & 0.15 to 0.20 & 5 & 0.12 \\
MTS & 0.10 to 0.15 & 12 & 0.17 \\
Selemion & 0.12 & 20 & 0.80
\end{tabular}

${ }^{a}$ IEC is expressed in milliequivalents of $\mathrm{H}^{+}$per gram of dry membrane.

brane increase as the affinity of the polymer to water decreases. ${ }^{22}$ Table 2 displays the thickness and the swelling capacity for the six HIPS/PAni membranes as well as for the commercial Selemion membrane. Water absorption is higher for the membranes produced in solution ((7 to 12) \% for MCS, MDS, and MTS) than for those obtained by mechanical mixing ((4 to 5) $\%$ for MCP, MDP, and MTP), although the former are thicker than the latter. This behavior is consistent with the tubular microchannels previously observed by scanning electron microscopy for the membranes prepared by solvent dissolution. ${ }^{17}$ Thus, membranes obtained by pressing the mechanical mixture are less porous than those produced by evaporating the solvent of solution dispersions. On the other hand, the swelling is higher for the TSA-doped membranes than for those containing DBSA and CSA, which should be attributed to the higher hydrophilicity of the former acid. In spite of this, the water uptake is one order of magnitude higher for the Selemion membrane than for the HIPS/PAni ones in all cases with exception of the MTS, in which the difference decreases to $8 \%$.

The IEC measured for HIPS/PAni and Selemion membranes are included in Table 2. As it can be seen, the IEC is relatively similar for all of the HIPS/PAni membranes, which is consistent with the fact that the concentration of PAni is identical in all cases, that is, the amount of $\mathrm{SO}_{3}{ }^{-}$functional groups acting in the transport of ions is the same in all of the HIPS/PAni membranes. The slightly higher IEC values found for the MCS and MTS membranes ( 0.20 and 0.17 , respectively) should be attributed to the hydrophilic character of the CSA and TSA dopants combined with the porous structure of the membranes produced in solution. On the other hand, the IEC determined for the Selemion membrane is around five times higher that those for the HIPS/PAni ones.

Polarization Curves. The electric resistance of the membranes prepared by mechanical mixing was very high [(11.0, 6.2, and 9.6) $\Omega \cdot \mathrm{cm}^{-1}$ for MCP, MDP, and MTP, respectively] compared to those of the membranes produced in solution [(4.2, 0.2, and 8.7) $\Omega \cdot \mathrm{cm}^{-1}$ for MCS, MDS, and MTS, respectively]. Accordingly, $i-\phi_{\mathrm{m}}$ curves with $\mathrm{Na}^{+}, \mathrm{Ni}^{2+}$, and $\mathrm{Cr}^{3+}$ were only recorded for the latter membranes as well as for the commercial Selemion one, the results being compared in Figure 2. All of these profiles show the three characteristic regions of ion-selective membranes. In the first region, which occurs at low $i$ values, the linear relation with $\phi_{\mathrm{m}}$ indicates the quasi-equilibrium state in the interface between the membrane and the solution. Such a linear tendency is lost in the second region, allowing identify the limiting current $\left(i_{\text {lim }}\right)$ value in each case. The values of $i_{\text {lim }}$ obtained for the different membranes are displayed in Table 3. The change in the behavior of the membrane potential is due to the concentration polarization, which is produced by the difference between the ionic transport in the solution and in the membrane. Thus, while the $i-\phi_{\mathrm{m}}$ relationship is governed by the Ohm's law when $i$ is low, an appreciable potential rise 


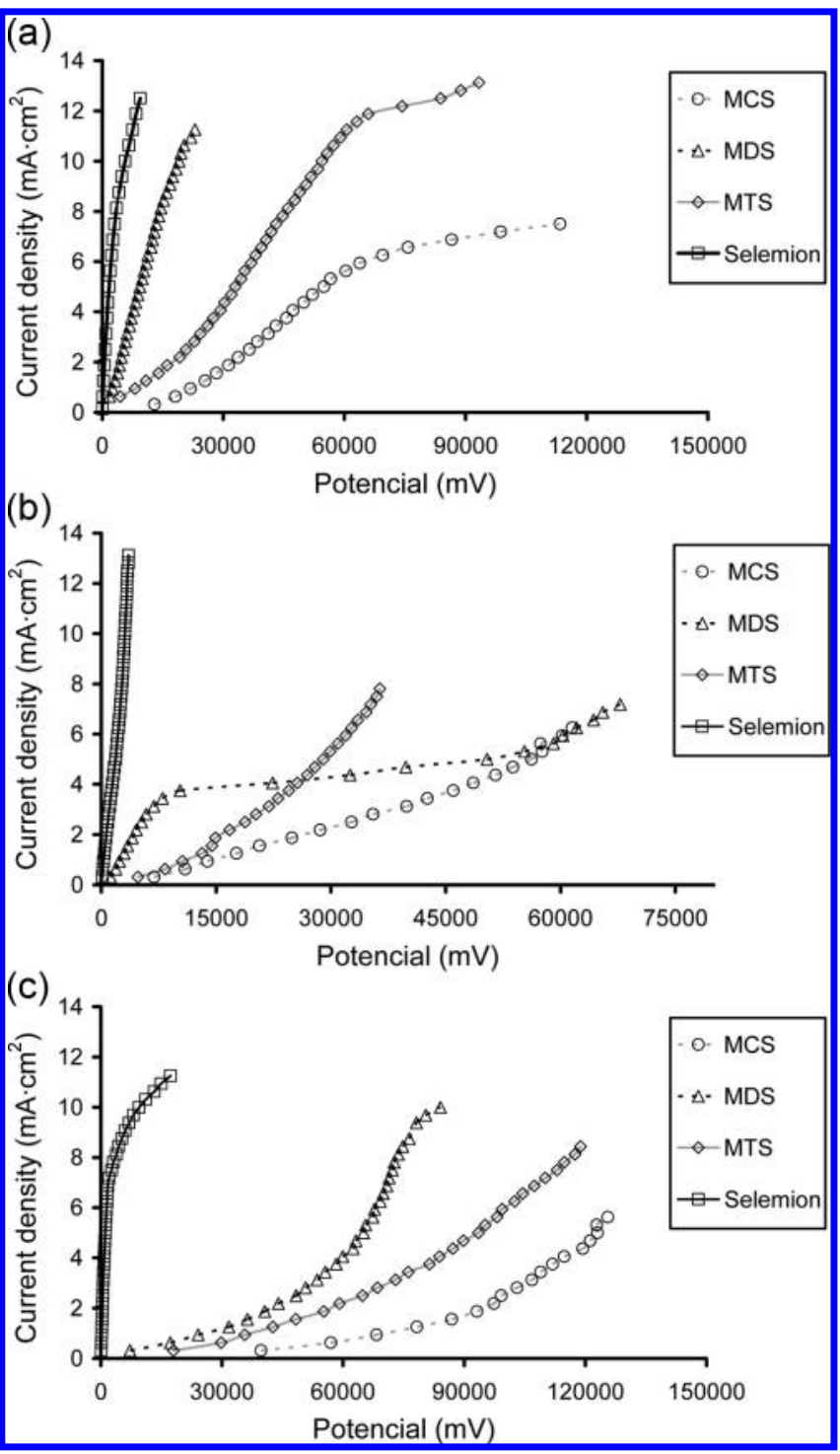

Figure 2. Polarization curves of MCS, MDS, MTS, and Selemion membranes in (a) $0.1 \mathrm{M} \mathrm{NaCl}$, (b) $0.1 \mathrm{M} \mathrm{NiCl}_{2}$, and (c) $0.1 \mathrm{M} \mathrm{CrCl}_{3}$ solutions.

is detected at above $i_{\mathrm{lim}}$. The current density surpasses the value of $i_{\text {lim }}$ in the third region. This increment should be attributed to other processes (e.g., chemical dissociation of water molecules, exaltation of ions, gravitational convection, and electroconvection) accompanying the polarization produced by the variation in the concentration of ions. ${ }^{34}$ The $i_{\text {lim }}$ used for the electrodialysis assays with the MCS, MDS, MTS, and Selemion membranes was $3 \mathrm{~mA} \cdot \mathrm{cm}^{-2}$, which approximately corresponds to $70 \%$ of the $i_{\text {lim }}$ values determined for the three examined ions (Table 3).

$\mathrm{Na}^{+}, \mathrm{Ni}^{2+}$, and $\mathrm{Cr}^{3+}$ Extraction. Table 3 lists the percentage of $\mathrm{Na}^{+}, \mathrm{Ni}^{2+}$, and $\mathrm{Cr}^{3+}$ extracted through the membranes. For the membranes produced in solution, the largest transport of $\mathrm{Na}^{+}, \mathrm{Ni}^{2+}$, and $\mathrm{Cr}^{3+}$ was found for the MTS (3.2\%), MCS $(2.6 \%)$, and $\operatorname{MDS}(7.0 \%)$, respectively. These values were comparable to those obtained using the commercial Selemion (5.4 \% , 3.6\% , and $21.9 \%$ for $\mathrm{Na}^{+}, \mathrm{Ni}^{2+}$, and $\mathrm{Cr}^{3+}$, respectively). Unfortunately, electrodialysis assays using the membranes produced by mechanical mixture were only possible in a few cases (see Table 3), in which the applied current density was increased from ( 3 to 5 ) $\mathrm{mA} \cdot \mathrm{cm}^{-2}$, because of their high electric resistance. However, it should be emphasized that the $\mathrm{Na}^{+}$and $\mathrm{Ni}^{2+}$ percent extraction of the MCP membrane $(10.3 \%$ and 15.4 $\%$, respectively) was very similar to that of the Selemion (10.4 $\%$ and $20.4 \%$, respectively) under identical experimental conditions.

The differences showed by the different membranes in the extraction of $\mathrm{Na}^{+}, \mathrm{Ni}^{2+}$, and $\mathrm{Cr}^{3+}$ should be mainly attributed to two factors: (i) the doping agent and (ii) the procedure used to produce the membrane. The only chemical difference among the membranes produced in this work corresponds to the doping agent, since the HIPS:PAni ratio is identical in all cases. Thus, TSA and DBSA are aromatic acids, while CSA is a cyclic acid. This chemical difference may affect the electronic structure of the $\mathrm{SO}_{3}{ }^{-}$groups, which are responsible of the ionic transport, or even the interaction between these groups and the nitrogen atoms of PAni. On the other hand, the alkyl group of DBSA may induce unfavorable steric interactions, altering the ionic transport. This is consistent with the percent extraction of $\mathrm{Na}^{+}$ and $\mathrm{Ni}^{2+}$, which was significantly lower through the MDS than through the MTS and MCS, respectively. However, the extraction of $\mathrm{Cr}^{3+}$ through the MDS membrane was the highest. The method used to produce the membrane has also a notable influence on the performance of the membrane. Thus, a comparison of the membranes produced in solution indicates that the extraction of $\mathrm{Na}^{+}$is considerably higher for the MTS than for the MCS and MDS, while among the membranes prepared by mechanical mixing the ionic transport through the MTS is significantly lower than through the MCP and MDP.

Quantum Mechanical Calculations on Dopant $\cdots(2 x+$ 2)-PAni Complexes. Table 4 lists the counterpoise corrected interaction energies, $\Delta E_{\text {int }}$, computed for CSA $\cdots(2 x+2)$-PAni, TSA $\cdots(2 x+2)$-PAni, and PBSA $\cdots(2 x+2)$-PAni complexes, with $x=0,1$, and 2 (Scheme 1). As it can be seen, the $\Delta E_{\mathrm{int}}$ values range from $(-373.7$ to -380.0$) \mathrm{kJ} \cdot \mathrm{mol}^{-1}$, from $(-296.6$ to -305.9$) \mathrm{kJ} \cdot \mathrm{mol}^{-1}$, and from $(-276.5$ to -286.2$) \mathrm{kJ} \cdot \mathrm{mol}^{-1}$ for complexes with $x=0,1$, and 2 , respectively. Thus, the strength of the dopant $\cdots(2 x+2)$-PAni interaction decreases

Table 3. Limiting Current $\left(i_{\mathrm{lim}}\right)$, Percent Extraction $\left(E_{\%}\right)$, and Extraction in $\mathbf{m g} \cdot \mathrm{L}^{-1}\left(E_{\left.\mathrm{mg} \cdot \mathrm{L}^{-1}\right)}\right.$ of $\mathrm{Na}^{+}, \mathrm{Ni}^{2+}$, and $\mathrm{Cr}{ }^{3+}$ for $\mathrm{HIPS} / \mathrm{PAni}$ and Selemion Membranes

\begin{tabular}{|c|c|c|c|c|c|c|c|}
\hline \# & MCS & MDS & MTS & MCP & MDP & MTP & Selemion \\
\hline$i_{\lim } \mathrm{Na}^{+a}$ & 5.62 & 8.43 & 11.56 & $b$ & $b$ & $b$ & 5.00 \\
\hline$i_{\lim } \mathrm{Cr}^{3+a}$ & 4.69 & 9.38 & 10 & $b$ & $b$ & $b$ & 7.19 \\
\hline$E_{\%} \mathrm{Ni}^{2+}$ & $2.6^{c}$ & $0.8^{c}$ & $1.0^{c}$ & $15.4^{d}$ & $b$ & $b$ & $3.6^{c} / 20.4^{d}$ \\
\hline$E_{\mathrm{m} \cdot \cdot \mathrm{L}^{-1}} \mathrm{Ni}^{2+}$ & $60^{c}$ & $20^{c}$ & $20^{c}$ & $500^{d}$ & $b$ & $b$ & $90^{c} / 700^{d}$ \\
\hline$E_{\sigma} \mathrm{Cr}^{3+}$ & $5.1^{c}$ & $7.0^{c}$ & $2.4 b$ & $b$ & $b$ & $b$ & $21.9^{c} / 28.6^{d}$ \\
\hline
\end{tabular}

${ }^{a} \mathrm{In} \mathrm{mA} \cdot \mathrm{cm}^{-2} .{ }^{b}$ Not determined due to the electrical resistance of the membrane. ${ }^{c} i=3 \mathrm{~mA} \cdot \mathrm{cm}^{-2}$, area of the membrane $=10 \mathrm{~cm}^{2} .{ }^{d} i=5$ $\mathrm{mA} \cdot \mathrm{cm}^{-2}$, area of the membrane $=10 \mathrm{~cm}^{2}$. 
Table 4. Counterpoise Corrected Interaction Energies $\left(\Delta E_{\text {int }}\right.$; in $\left.\mathbf{k J} \cdot \mathrm{mol}^{-1}\right)$ and Relevant Intermolecular Parameters $\left(d_{\mathrm{H}} \cdots \mathrm{O}\right.$ and $<\mathrm{N}-\mathrm{H} \cdots \mathrm{O}$; in $\AA$ and Degrees, Respectively) for the Dopant $\cdots(2 x+2)$-PAni Complexes with $x=0,1$, and 2 Obtained at the UB3LYP/6-31G(d) Level

\begin{tabular}{|c|c|c|c|c|c|c|c|c|c|}
\hline \multirow[b]{2}{*}{ \# } & \multicolumn{3}{|c|}{$x=0$} & \multicolumn{3}{|c|}{$x=1$} & \multicolumn{3}{|c|}{$x=2$} \\
\hline & $\Delta E_{\mathrm{int}}$ & $d_{\mathrm{H}} \cdots \mathrm{O}$ & $<\mathrm{N}-\mathrm{H} \cdots \mathrm{O}$ & $\Delta E_{\mathrm{int}}$ & $d_{\mathrm{H}} \cdots \mathrm{O}$ & $<\mathrm{N}-\mathrm{H} \cdots \mathrm{O}$ & $\Delta E_{\mathrm{int}}$ & $d_{\mathrm{H} \cdots \mathrm{O}}$ & $<\mathrm{N}-\mathrm{H} \cdots \mathrm{O}$ \\
\hline CSA & -373.7 & 1.506 & 175.6 & -296.6 & 1.660 & 168.1 & -276.5 & 1.644 & 167.9 \\
\hline TSA & -380.0 & 1.508 & 169.0 & -305.9 & 1.630 & 168.2 & -286.2 & 1.639 & 166.8 \\
\hline
\end{tabular}

when $x$ increases, this reduction being due to the spread of the positive charge through $\pi$-system of the oligoaniline chain. ${ }^{35}$ In spite of this effect, the $\Delta E_{\text {int }}$ gap remains practically unaltered in all cases, that is, the gap is $\left(6.3,9.2\right.$, and 9.6) $\mathrm{kJ} \cdot \mathrm{mol}^{-1}$ for complexes involving 2-PAni, 4-PAni, and 6-PAni, respectively. The variation of the strength of the interaction with $x$ is consistent with the values of $d_{\mathrm{H}} \cdots \mathrm{O}$ and $<\mathrm{N}-\mathrm{H} \cdots \mathrm{O}$, which are included in Table 4. Moreover, a detailed inspection of the $\Delta E_{\text {int }}$ values reveals that the energetic preferences of the oligoanilines toward the different dopants do not depend on the size of the former, the strength of the interaction following the same order for complexes with $x=0,1$, and 2 : TSA $\approx$ PBSA $>$ CSA. On the other hand, the geometry of the optimized complexes is illustrated in Figure 3, which displays the three complexes obtained for $x=1$.

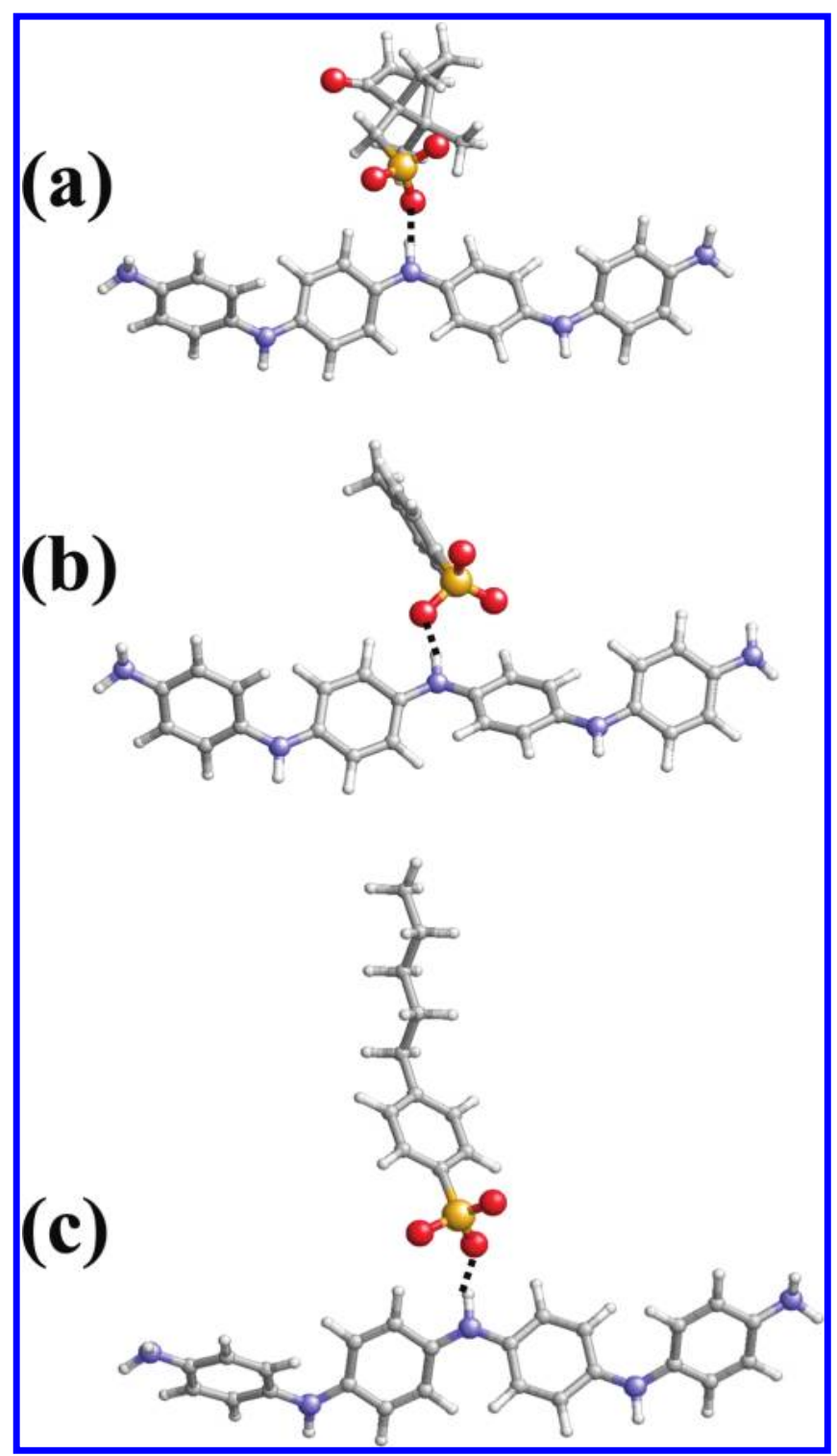


TSA $\cdots 4$-PAni, and (c) PBSA $\cdots 4$-PAni complexes.
Table 5. NBO Charges Calculated at the UB3LYP/6-31G(d) Level for the Deprotonated Dopants in Both the Free State and Forming Dopant $\cdots(2 x+2)$-PAni Complexes (with $x=0,1$ and 2$)^{a}$

\begin{tabular}{lccc}
\hline \multicolumn{1}{c}{$\#$} & $\mathrm{Q}_{\mathrm{T}}$ & $Q_{\mathrm{X}}$ & $Q_{\mathrm{SO}_{3}}$ \\
\hline CSA (free) & -1.000 & -0.316 & -0.684 \\
CSA $\cdots$ 2-PAni & -0.850 & -0.209 & -0.641 \\
CSA $\cdots$ 4-PAni & -0.875 & -0.220 & -0.655 \\
CSA $\cdots$ 6-PAni & -0.871 & -0.214 & -0.657 \\
TSA (free) & -1.000 & -0.357 & -0.643 \\
TSA $\cdots$ 2-PAni & -0.822 & -0.233 & -0.589 \\
TSA $\cdots$ 4-PAni & -0.870 & -0.248 & -0.622 \\
TSA $\cdots$ 6-PAni & -0.870 & -0.250 & -0.620 \\
PBSA (free) & 1.000 & -0.228 & -0.601 \\
PBSA $\cdots$ 2-PAni & -0.829 & -0.228 & -0.601 \\
PBSA $\cdots$ 4-PAni & -0.870 & -0.252 & -0.618 \\
PBSA $\cdots$ 6-PAni & -0.875 & -0.255 & -0.620
\end{tabular}

${ }^{a} Q_{\mathrm{T}}, Q_{\mathrm{X}}$, and $Q_{\mathrm{SO}_{3}}$ refer to the charge on the whole dopant $\left(\mathrm{X}-\mathrm{SO}_{3}{ }^{-}\right.$ in Scheme 1), on the group $\mathrm{X}$, and on the $\mathrm{SO}_{3}{ }^{-}$moiety, respectively. Charges are in atomic units.

Table 5 shows the total charge of dopant molecule $\left(Q_{\mathrm{T}}\right)$ for the calculated dopant $\cdots(2 x+2)$-PAni complexes. As can be seen, in the complexes $Q_{\mathrm{T}}$ ranges from -0.822 to -0.875 units of electron indicating that the dopant transmits approximately 0.129 to 0.178 units of electron to the oligoaniline. Moreover, such a charge transfer effect systematically decreases when the size of the oligoaniline increases. A more detailed analysis of the charge reveals subtle but systematic differences between CSA and the two dopants with aromatic groups, which follow an almost identical behavior. Thus, $Q_{\mathrm{SO}_{3}}$ and $Q_{\mathrm{X}}$, which correspond to the charges on the $\mathrm{SO}_{3}{ }^{-}$moiety and the rest of the dopant molecule ( $\mathrm{X}$ in Scheme 1), respectively, reflect that the concentration of negative charge in the $\mathrm{SO}_{3}{ }^{-}$moiety is slightly larger, that is, around 0.04 to 0.05 units of electron, in complexes with CSA than in complexes with TSA and PBSA, this trend being completely independent of the size of the oligoaniline. Accordingly, the strength of the interaction in dopant-PAni complexes decreases when the concentration of negative charge on the $\mathrm{SO}_{3}{ }^{-}$group increases.

Quantum Mechanical Calculations on Dopant $\cdot$.'M Complexes. Complete geometry optimizations of CSA $\cdots \mathrm{M}$, TSA $\cdots \mathrm{M}$, and PBSA $\cdots M$ complexes with $\mathrm{M}=\mathrm{Na}^{+}, \mathrm{Ni}^{2+}$, and $\mathrm{Cr}^{3+}$ were performed at both the UB3LYP/6-31G(d) and UMP2/6$31+\mathrm{G}(\mathrm{d}, \mathrm{p})$ levels, the latter method being expected to provide a more reliable description of complexes involving metallic ions. The counterpoise corrected $\Delta E_{\text {int }}$ values, which are listed in Table 6 , indicate that the two theoretical levels provide similar results from a qualitative point of view, although significant quantitative differences are detected. Thus, the $\Delta E_{\text {int }}$ values obtained using the UB3LYP method are overestimated with respect to those derived from UMP2 calculations, this effect increasing rapidly with the charge of the metallic ion. In spite of this, the two theoretical methods predict that the highest binding affinity of $\mathrm{Na}^{+}, \mathrm{Ni}^{2+}$, and $\mathrm{Cr}^{3+}$ corresponds to the CSA, TSA, and CSA doping agent, respectively.

Table 7 lists the values of $Q_{\mathrm{T}}, Q_{\mathrm{SO}_{3}}$, and $Q_{\mathrm{X}}$ for the dopant molecule in the dopant $\cdots M$ complexes calculated at the UMP2/ 6-31+G(d,p) level. As can be seen, the $Q_{\mathrm{T}}$ values indicate that CSA, TSA, and PBSA transfer a negative charge to the metal 
Table 6. Counterpoise Corrected Interaction Energies (in $\mathbf{k J} \cdot \mathrm{mol}^{-1}$ ) for the Dopant $\cdots \mathrm{M}$ Complexes with $\mathrm{M}=\mathrm{Na}^{+}, \mathrm{Ni}^{2+}$, and $\mathrm{Cr}^{3+} \mathrm{Obtained}$ at the UB3LYP/6-31G(d) and UMP2/6-31+G(d,p) Levels

\begin{tabular}{cccccrr}
\hline & \multicolumn{3}{c}{ UB3LYP/6-31G(d) } & & \multicolumn{3}{c}{ UMP2/6-31+G(d,p) } \\
\cline { 2 - 4 } \cline { 3 - 6 } $\mathrm{M}$ & CSA & TSA & PBSA & & CSA & TSA \\
\hline $\mathrm{Na}^{+}$ & -552.2 & -539.7 & -538.4 & -517.5 & -507.0 & -506.1 \\
$\mathrm{Ni}^{2+}$ & -1725.9 & -1746.4 & -1700.7 & -1506.3 & -1566.2 & -1538.1 \\
$\mathrm{Cr}^{3+}$ & -3468.5 & -3211.6 & -3248.9 & -3285.8 & -2898.2
\end{tabular}

Table 7. NBO Charges Calculated at the UMP2/6-31+G(d,p) Level for the Deprotonated Dopants Forming Dopant $\cdots$ M Complexes $\left(\text { with } \mathrm{M}=\mathrm{Na}^{+}, \mathrm{Ni}^{2+} \text {, and } \mathrm{Cr}^{3+}\right)^{a}$

\begin{tabular}{crrr}
\hline$\#$ & \multicolumn{1}{c}{$Q_{\mathrm{T}}$} & \multicolumn{1}{c}{$Q_{\mathrm{X}}$} & \multicolumn{1}{c}{$Q_{\mathrm{SO}_{3}}$} \\
\hline $\mathrm{CSA} \cdots \mathrm{Na}^{+}$ & -0.953 & -0.145 & -0.809 \\
$\mathrm{CSA} \cdots \mathrm{Ni}^{2+}$ & -0.705 & 0.010 & -0.715 \\
$\mathrm{CSA} \cdots \mathrm{Cr}^{3+}$ & 0.266 & 0.940 & -0.674 \\
$\mathrm{TSA} \cdots \mathrm{Na}^{+}$ & -0.943 & -0.160 & -0.783 \\
$\mathrm{TSA} \cdots \mathrm{Ni}^{2+}$ & -0.699 & -0.024 & -0.674 \\
$\mathrm{TSA} \cdots \mathrm{Cr}^{3+}$ & 0.266 & 0.296 & -0.030 \\
$\mathrm{PBSA} \cdots \mathrm{Na}^{+}$ & -0.943 & -0.160 & -0.783 \\
PBSA $\cdots \mathrm{Ni}^{2+}$ & -0.672 & 0.046 & -0.718 \\
PBSA $\cdots \mathrm{Cr}^{3+}$ & 0.269 & 0.867 & -0.598
\end{tabular}

${ }^{a} Q_{\mathrm{T}}, Q_{\mathrm{X}}$, and $Q_{\mathrm{SO}_{3}}$ refers to the charge on the whole dopant $\left(\mathrm{X}-\mathrm{SO}_{3}{ }^{-}\right.$ in Scheme 1), on the group $\mathrm{X}$, and on the $\mathrm{SO}_{3}{ }^{-}$moiety, respectively. Charges are in atomic units.

cations when forming the complexes, the amount of charge being bigger as the charge of the cation increases. Moreover, for a given $\mathrm{M}$, the charge transferred is almost independent of the dopant. On the other hand, the $Q_{\mathrm{SO}_{3}}$ quantities listed in the table point out that the concentration of negative charge in the $\mathrm{SO}_{3}{ }^{-}$moiety is generally higher in complexes with CSA than in complexes with TSA and PBSA, which is consistent with the results obtained in dopant $\cdots(2 x+2)$-PAni complexes.

\section{Conclusions}

Six different HIPS/PAni membranes have been produced using three different doping agents (DBSA, CSA, and TSA) and two preparation methods (mechanical mixture and solvent dissolution). The most remarkable results derived from their characterization can be summarized as follows: (i) the membranes produced in solution showed a higher absorption of water than those prepared by pressing the mechanical mixture; (ii) the swelling capacity was higher for the membranes doped with TSA than for those doped with DBSA and CSA; and (iii) the IEC was similar for the six HIPS/PAni membranes. However, both the water uptake and IEC of the commercial Selemion membrane were the highest.

For the membranes prepared in solution, the $i_{\text {lim }}$ used for the electrodialysis assays, $3 \mathrm{~mA} \cdot \mathrm{cm}^{-2}$, was derived from the $i-\phi_{\mathrm{m}}$ curves obtained in a five-compartment cell. The largest transport of $\mathrm{Na}^{+}, \mathrm{Ni}^{2+}$, and $\mathrm{Cr}^{3+}$ was found for the MTS, MCS, and MDS, respectively, the percentage extraction in these membranes being comparable to those obtained for the Selemion. Measure of the extraction of ions through the membranes produced by mechanical mixture was only possible in a few cases because of their high electric resistance. The overall experimental results evidenced that the transport of ions through the HIPS/PAni membranes depends on both the doping agent and the preparation method. Thus, the preparation method determines the porosity and electrical resistance of the membranes, while the dopant affects the electronic structure of the $\mathrm{SO}_{3}{ }^{-}$groups.

Quantum mechanical calculations on CSA $\cdots(2 x+2)$-PAni, TSA $\cdots(2 x+2)$-PAni, and PBSA $\cdots(2 x+2)$-PAni complexes with $x=0,1$, and 2 indicate that, independently of $x$, the strength of the interaction between the $\mathrm{CP}$ and the doping agent follows this order: TSA $\approx$ PBSA $>$ CSA. On the other hand, ab initio and DFT calculations on CSA $\cdots \mathrm{M}$, TSA $\cdots \mathrm{M}$, and PBSA $\cdots M$ complexes, where $\mathrm{M}$ is the metallic ion, revealed that for $\mathrm{Na}^{+}, \mathrm{Ni}^{2+}$, and $\mathrm{Cr}^{3+}$ the strongest interaction is obtained for CSA, TSA, and CSA, respectively. In both dopant $\cdots(2 x+$ 2)-PAni and dopant $\cdots M$ complexes, the largest concentration of negative charge in the $\mathrm{SO}_{3}{ }^{-}$moiety of the dopants is found in the complexes with CSA.

\section{Literature Cited}

(1) Mishra, A.; Ma, C. Q.; Baüerle, P. Functional Oligothiophenes: Molecular Design for Multidimensional Nanoarchitecture and Their Applications. Chem. Rev. 2009, 109, 1141-1276.

(2) Roncali, J. Synthetic Principles for Bandgap Control in Linear $\pi$-Conjugated Systems. Chem. Rev. 1997, 97, 173-205.

(3) Skotheim, T. A.; Reynolds, J. R. Handbook of Conducting Polymers, 3rd ed.; CRC Press: Boca Raton, 2007.

(4) Chan, H. S. O.; Ng, S. C. Synthesis, Characterization and Applications of Thiophene-based Functional Polymers. Prog. Polvm. Sci. 1998, 23, $1167-1231$

(5) Armelin, E.; Pla, R.; Liesa, F.; Ramis, X.; Iribarren, J. I.; Alemán, C. Corrosion Protection with Polyaniline and Polypyrrole as Anticorrosive Additive for Epoxy Paints. Corros. Sci. 2008, 50, 721-728.

(6) Armelin, E.; Menneguzzi, A.; Ferreira, C. A.; Alemán, C. Polyaniline, Polypyrrole and Poly(3,4-ethylenedioxythiophene) as Additives of Organic Coatings to Prevent Corrosion. Surf. Coat. Technol. 2009, 203, 3763-3769.

(7) Bobacka, J. Conducting Polymer-based Solid-State Ion-Selective Electrodes. Electroanalvsis 2006, 18, 7-18.

(8) Zhao, L.; Zhao, L.; Xu, Y.; Qiu, T.; Zhi, L.; Shi, G. Polyaniline Electrochromic Devices with Transparent Graphene Electrodes. Electrochim. Acta 2009, 55, 491-497.

(9) Li, H.; Xie, K.; Pan, Y.; Yao, M.; Xin, C. Variable Emissivity Infrared Electrochromic Device Based on Polyaniline Conducting Polymer. Synth. Met. 2009, 159, 1386-1388.

(10) Chen, C. C.; Do, J. S.; Gu, Y. Immobilization of HPR in Mesoporous Silica and Its Application for the Construction of Polyaniline Modified Hydrogen Peroxyde Biosensor. Sensor 2009, 9, 4635-4648.

(11) Singh, V.; Mohan, S.; Singh, G.; Pandey, P. C.; Prakash, R. Synthesis and Characterization of Polyaniline-Carboxylated PVC Composites: Application in Development of Ammonia Sensor. Sens. Actuators, B 2008, 132, 99-106.

(12) Gupta, B.; Prakash, R. Processible Polyacid Doped Polyaniline Composites: Application for Charge Store Devices. Mater. Sci. Eng. 2009, 29, 1746-1751.

(13) Rath, S. S. K.; Hande, V. R.; Thakur, A. P.; Patri, M.; Samui, A. B. All-Solid Supercapacitor Based on Polyaniline and Sulfonated Polymers. Svnth. Met. 2006, 156, 1057-1064.

(14) Rojas, A. M.; Olivares-Maldonado, Y.; Torres Rodríguez, M. L. An Easy Method to Modify the Exchange Membranes of Electrodialysis with Electrosynthetized Polyaniline. J. Membr. Sci. 2007, 300, 2-5.

(15) Amado, F. D. R.; Gondran, E.; Ferreira, J. Z.; Rodrigues, M. A. S.; Ferreira, C. A. Synthesis and Characterization of High Impact Polystyrene/Polyaniline Composite Membranes for Electrodialysis. $\underline{.}$. Membr. Sci. 2004, 234, 139-145.

(16) Amado, F. D. R.; Rodrigues, M. A. S.; Morisso, F. D. P.; Bernardes, A. M.; Ferreira, J. Z.; Ferreira, C. A. High-Impact Polystyrene/ Polyaniline Membranes for Acid Solution Treatment by Electrodialysis: Preparation, Evaluation and Chemical Calculation. J. Colloid Interface Sci. 2008, 320, 52-61.

(17) Amado, F. D. R.; Rodrigues, M. A.; Bertuol, D. A.; Bernardes, A. M.; Ferreira, J. Z.; Ferreira, C. A. The Effect of Production Method on the Properties of High Impact Polystryrene and Polyaniline Membranes. J. Membr. Sci. 2009, 330, 227-232.

(18) Campos, T. L. A.; Kersting, D. F.; Ferreira, C. A. Chemical Synthesis of Polyaniline Using Sulphanilic Acid as Dopant Agent into the Reactional Medium. Surf. Coat. Technol. 1999, 122, 3-5.

(19) MacDiarmid, A. G.; Epstein, A. J. Polyanilines: A Novel Class of Conducting Polymer. Faraday Discuss. Chem. Soc. 1989, 88, 317332. 
(20) Scherer, R.; Bernardes, A. M.; Forte, M. M. C.; Ferreira, J. Z.; Ferreira, C. A. Preparation and Physical Characterization of a Sulfonated Poly(styrene-co-divinylbenzene) and Polypyrrole Composite Membranes. Mater. Chem. Phys. 2001, 71, 131-136.

(21) Cui, W.; Kerres, J.; Eigenberger, G. Development and Characterization of Ion-Exchange Polymer Blend Membranes. Sep. Purif. Technol. 1998, 14, 145-154.

(22) Strathmann, H. Electrodialysis and related processes. In Membrane Separations Technology - Principles and Applications: Noble, R. D., Stern, S., Eds.; Elsevier: New York, NY, 1995; pp 213-281.

(23) Tanaka, Y. Concentration Polarization Ion-Exchange Membrane Electrodyalisis - The Events Arising in a Flowing Solution in a Desalting Cell. J.Membr. Sci. 2003, 216, 149-164.

(24) Casanovas, J.; Canales, M.; Ferreira, C. A.; Alemán, C. A First Principle Analysis of the Structure of Oligoanilines Doped with Alkylsulfonic Acids. J. Phvs. Chem. A 2009, 113, 8795-8800.

(25) Becke, A. D. A New Mixing of Hartree-Fock and Local Density Functional Theories. J. Chem. Phvs. 1993, 98, 1372-1378.

(26) Lee, C.; Yang, W.; Parr, R. G. Development of the Colle-Salvetti Correlation-Energy Formula into a Functional of the Electron Density. Phvs. Rev. B 1988, 37, 785-789.

(27) Hariharan, P. C.; Pople, J. A. Influence of Polarization Functions on Molecular-Orbital Hydrogenation Energies. Theor. Chim. Acta 1973, 28, 213-222.

(28) Møller, C.; Plesset, M. S. Note on an Approximation Treatment for Many-Electron Systems. Phvs. Rev. 1934, 46, 618-622.

(29) McLean, A. D.; Chandler, G. S. Contracted Gaussian-Basis Sets for Molecular Calculations. 1. 2nd Row Atoms, $\mathrm{Z}=11-18$. J. Chem. Phvs. 1980, 72, 5639-5648.

(30) Boys, S. F.; Bernardi, F. Calculation of Small Molecular Interactions by Differences of Separate Total Energies - Some Procedures with Reduced Errors. Mol. Phvs. 1970, 19, 553-566.

(31) Reed, A. E.; Weinhold, F. Natural-Population Analysis. J. Chem. Phvs. 1985, 83, 735-746.

(32) Reed, A. E.; Curtiss, L. A.; Weinhold, F. Intermolecular Interactions from a Natural Bond Orbital, Donor-Acceptor Viewpoint. Chem. Rev. 1988, 88, 899-926.
(33) Frisch, M. J.; Trucks, G. W.; Schlegel, H. B.; Scuseria, G. E.; Robb, M. A.; Cheeseman, J. R.; Montgomery, J. A., Jr.; Vreven, T.; Kudin, K. N.; Burant, J. C.; Millam, J. M.; Iyengar, S. S.; Tomasi, J.; Barone, V.; Mennucci, B.; Cossi, M.; Scalmani, G.; Rega, N.; Petersson, G. A.; Nakatsuji, H.; Hada, M.; Ehara, M.; Toyota, K.; Fukuda, R.; Hasegawa, J.; Ishida, M.; Nakajima, T.; Honda, Y.; Kitao, O.; Nakai, H.; Klene, M.; Li, X.; Knox, J. E.; Hratchian, H. P.; Cross, J. B.; Adamo, C.; Jaramillo, J.; Gomperts, R.; Stratmann, R. E.; Yazyev, O.; Austin, A. J.; Cammi, R.; Pomelli, C.; Ochterski, J. W.; Ayala, P. Y.; Morokuma, K.; Voth, G. A.; Salvador, P.; Dannenberg, J. J.; Zakrzewski, V. G.; Dapprich, S.; Daniels, A. D.; Strain, M. C.; Farkas, O.; Malick, D. K.; Rabuck, A. D.; Raghavachari, K.; Foresman, J. B.; Ortiz, J. V.; Cui, Q.; Baboul, A. G.; Clifford, S.; Cioslowski, J.; Stefanov, B. B.; Liu, G.; Liashenko, A.; Piskorz, P.; Komaromi, I.; Martin, R. L.; Fox, D. J.; Keith, T.; Al-Laham, M. A.; Peng, C. Y.; Nanayakkara, A.; Challacombe, M.; Gill, P. M. W.; Johnson, B.; Chen, W.; Wong, M. W.; Gonzalez, C.; Pople, J. A. Gaussian 03, revision B.02; Gaussian, Inc.: Pittsburg, PA, 2003.

(34) Mishchuk, N. A. Perspectives of the Electrodialysis Intensification. Desalination 1998, 117, 283-296.

(35) Alemán, C.; Ferreira, C. A.; Torras, J.; Meneguzzi, A.; Canales, M.; Rodrigues, M. A. S.; Casanovas, J. On the Molecular Properties of Polyaniline: A Comprehensive Theoretical Study. Polvmer 2008, 49 , 5169.

Received for review April 22, 2010. Accepted September 3, 2010. This work has been supported by MICINN and FEDER (Grants MAT200909138 and PHB2007-0038-PC), by the Generalitat de Catalunya (research group 2009 SGR 925 and XRQTC) and by CAPES-MICINN International Cooperation Program from Brazilian and Spanish Education and Science Ministries. Computer resources were generously provided by the "Centre de Supercomputació de Catalunya" (CESCA). Support for the research of C.A. was received through the prize "ICREA Academia" for excellence in research funded by the Generalitat de Catalunya.

JE1004033 